\title{
APPLICATION OF LUMINESCENCE TECHNIQUES IN RETROSPECTIVE DOSIMETRY*
}

\author{
L. BøTTER-JENSEN ${ }^{a}$ AND H. JUNGNER ${ }^{b}$ \\ ${ }^{a}$ Ris $\varnothing$ National Laboratory, 4000 Roskilde, Denmark \\ ${ }^{b}$ Dating Laboratory, University of Helsinki, POB 11, 00014 Helsinki, Finland
}

(Received September 22, 1998; in final form November 16, 1998)

\begin{abstract}
Luminescence signals measured from minerals within bricks or ceramic samples can provide information about the absorbed radiation dose. This feature has for several years been used in dating archaeological and geological samples and recently luminescence techniques have been intensively used for retrospective assessment of accident doses received by the population after a nuclear accident. The development of new luminescence techniques after the Chernobyl accident has considerably improved the sensitivity and precision in the evaluation of accident doses. This paper reviews the development work, especially on optically stimulated luminescence methods for retrospective assessment of accident doses carried out at Ris $\varnothing$ National Laboratory in collaboration with the University of Helsinki as part of a joint European Union research project. We demonstrate that doses lower than $100 \mathrm{mGy}$ can be measured from extracted brick quartz with a precision in the order of $1 \%$ using newly developed optically stimulated luminescence dose evaluation protocols.
\end{abstract}

PACS numbers: $78.60 . \mathrm{Kn}, 87.53 . \mathrm{Bn}, 87.53 . \mathrm{Dq}$

\section{Introduction}

Luminescence methods especially designed to use natural materials for the reconstruction of accidental radiation doses in populated areas were developed and studied at Ris $\varnothing$ National Laboratory in collaboration with the Dating Laboratory, Helsinki University, as part of an European Union (EU) funded research project. Luminescence signals from minerals result either from thermal stimulation, called thermoluminescence (TL), or optical stimulation, called optically stimulated luminescence (OSL). In TL measurements samples have to be heated to approximately $500^{\circ} \mathrm{C}$ to release the entire signal. In OSL a suitable light source is used for stimulation. Ris $\varnothing$ proposed the use of OSL methods with ceramics in retrospective

*The results of this paper were initially presented at The Jablonski Centennial Conference on Luminescence and Photophysics, July 23-27, 1998, Torun', Poland. 
dosimetry rather than TL mainly because of the non-destructive nature of OSL measurements (no heating required) and thus we only report on the development and application of OSL methods in this paper.

OSL arises from the recombination of charge which has been optically released from electron traps within a crystal. The electron population in the traps is the result of exposure to ionizing radiation, and thus the OSL signal is related to the radiation dose. For experimental convenience, OSL emitted during recombination of the detrapped charges is usually measured in a spectral region different from that of the exciting photons. During exposure to the stimulation light the OSL signal is observed to decrease to a low level (decay curve) as the trapped charge is depleted. The physical principles of OSL are thus closely related to those associated with TL [1].

The potential of OSL in dating applications was first identified by Huntley et al. in 1985 [2]; they used the green light from an argon laser $(514 \mathrm{~nm})$ to stimulate luminescence from quartz for dating sediments. Later studies characterised the OSL properties of quartz in more detail with a view to establishing the technique as a tool for dating and dosimetry [3-5]. However, the expense of establishing such laser facilities restricted this technique to a limited number of laboratories. As a consequence, the observation by Hütt et al. [6] that OSL in feldspars could be stimulated with infrared wavelengths was of importance. This made possible the use of inexpensive and readily available IR light emitting diodes (LEDs) as the stimulation light source. Thus infrared stimulated luminescence (IRSL) rapidly became the most popular tool and several researchers constructed their own units for stimulation of feldspars, all based on systems of small IR LEDs [7-9]. Green LEDs at that time gave orders of magnitude less power than IR LEDs, and so the best alternative to lasers for visible light stimulation was the light spectrum obtained from heavy filtered halogen or xenon lamps [10].

As a result of these developments, the two main stimulation methods now in use in routine OSL measurements are: (1) IRSL which is useful only with feldspars and (2) visible (blue-green) light stimulated luminescence (GLSL) which provides signals from both feldspars and quartz. Blue and green light stimulation is also effective with porcelain and some synthetic materials such as $\mathrm{Al}_{2} \mathrm{O}_{3}: \mathrm{C}$ [11-13]. The difference in stimulation characteristics can be exploited in various ways, e.g. for testing the purity of quartz samples and for measurements of mixed samples $[10,14]$.

This paper reviews recent OSL instrument developments at Ris $\varnothing$ and describes new OSL techniques as well as analytical methods developed especially for use in retrospective dosimetry.

\section{OSL methods and techniques}

\subsection{IR stimulation}

The experience gained at Ris $\varnothing$ since the late 1970s with the development of automated TL readers for dating, and subsequent experiments carried out using infrared LEDs for optical stimulation of feldspars, resulted in 1990 in the development of an IRSL add-on unit to be mounted directly between the photomultiplier 
tube and the glow oven of the automated Ris $\varnothing$ TL apparatus [9]. Thirty two IR LEDs were arranged in two concentric rings. IRSL emitted vertically through the ring of diodes was then measured using the same photomultiplier tube as used for TL measurements. A BG-39 detection filter rejected the scattered IR light.

Normally IR LEDs peaking at $870-880 \mathrm{~nm}$ have been used for stimulation of feldspars. However, Godfrey Smith et al. [15] showed that the IR resonance measured for most feldspars peaks around $845-850 \mathrm{~nm}$. Recently IR LEDs peaking at $840 \mathrm{~nm}$ have become available. An array consisting of 30-40 IR diodes close to the sample $(10-20 \mathrm{~mm})$, deliver typically $40-50 \mathrm{~mW} / \mathrm{cm}^{2}$ at the sample position; this is useful in most OSL applications using both heated (archaeological) and unheated (geological) feldspars. In regeneration methods (see Sec. 3), in particular, higher power is needed for a complete depletion of the IRSL signal over a short time, to allow repeated regeneration of the IRSL from the same sample.
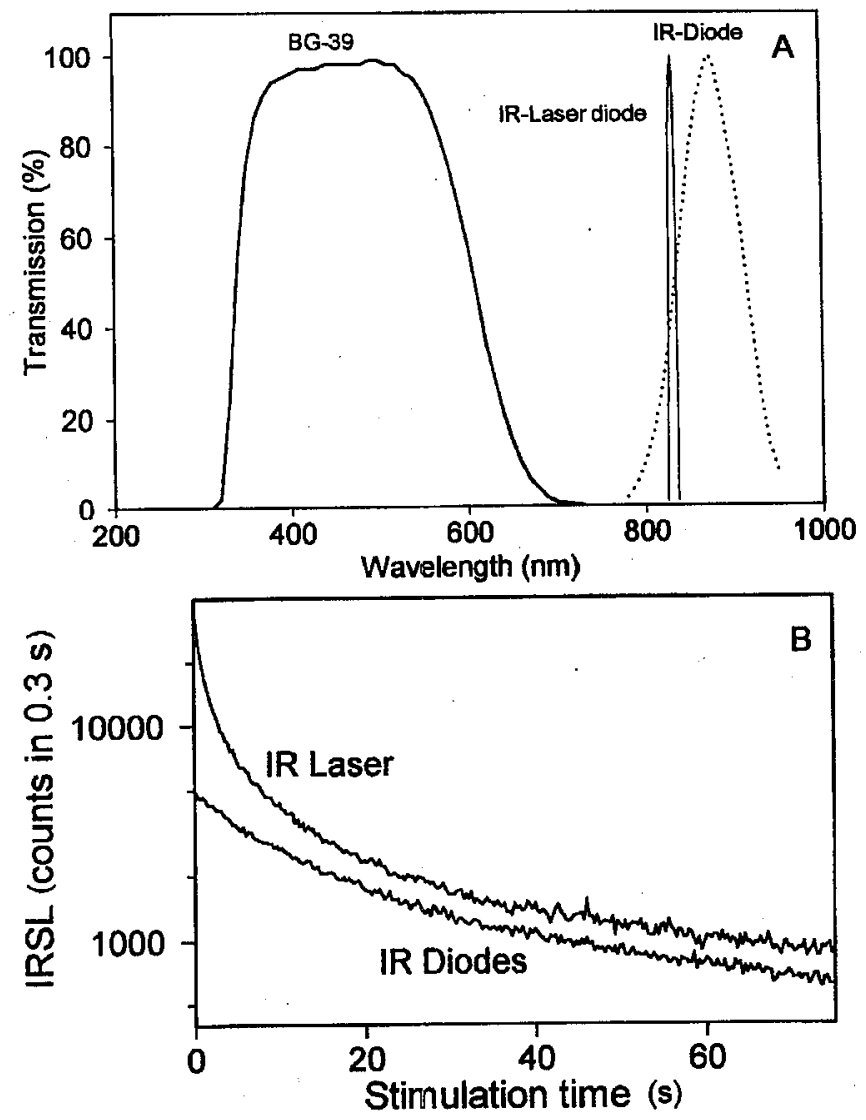

Fig. 1. (A) Characteristics for the BG-39 detection filter, the IR LED (type TEMPT 484) and the new solid state IR laser diode. (B) Plots of IRSL decay curves obtained from a feldspar sample using a normal LED array $\left(40 \mathrm{~mW} / \mathrm{cm}^{2}\right)$ and the new $1 \mathrm{~W} / 830 \mathrm{~nm}$ laser diode $\left(500 \mathrm{~mW} / \mathrm{cm}^{2}\right)$. Note the logarithmic $Y$-axis. 
Accordingly, we have recently investigated the application of solid state IR laser diodes, and have developed a compact IR stimulation unit based on a $1.0 \mathrm{~W}$ laser diode emitting at $830 \mathrm{~nm}$ [16]. Using appropriate optics, this provides a uniform illumination area of approximately $1 \mathrm{~cm}^{2}$ at the sample position. Figure $1 \mathrm{~A}$ shows the BG-39 detection filter transmission characteristics and the stimulation spectra from a typical IR LED and the IR laser diode. Typical IRSL decay curves from a feldspar sample obtained with (1) the laser diode running at $500 \mathrm{~mW} / \mathrm{cm}^{2}$ at the sample and (2) the conventional IR LED array $\left(40 \mathrm{~mW} / \mathrm{cm}^{2}\right)$ are shown in Fig. 1B. The greater stimulation power provided by the laser diode is seen to give an enhanced initial light output and a steeper initial OSL decay curve; the relative depletion after $75 \mathrm{~s}$ is much greater.

\subsection{Blue-green broad band stimulation}

Infrared stimulation produces luminescence from feldspars but not from quartz. The quartz OSL signal does not suffer from anomalous fading as is the case with feldspars [17] and thus the demand for OSL measurements of quartz led in 1991 to the development of a compact blue-green light stimulation system based on a simple low-power halogen lamp $(75 \mathrm{~W})$ rather than an expensive argon laser installation [10]: The OSL unit also incorporated a ring of IR LEDs at a short distance from the sample. The IRSL/GLSL unit was designed to be mounted onto the automated Ris $\varnothing$ TL apparatus, thus providing flexible combined IRSL/GLSL/TL features. In the standard mode the lamp was filtered to produce a stimulation wavelength band from $420-550 \mathrm{~nm}$ and delivered $16 \mathrm{~mW} / \mathrm{cm}^{2}$ to the sample. Signal detection was in the UV using U-340 filters with transmission peaking at $340 \mathrm{~nm}$. The OSL signals obtained from quartz were observed to decay at the same rate as those observed using an argon laser (514 nm) delivering $50 \mathrm{~mW} / \mathrm{cm}^{2}$ at the sample, mainly because of the higher energies present in the broad-band from the halogen lamp [10]. However, one problem encountered with this first type of broad band stimulation system was that the halogen lamps only had an effective lifetime of approximately 30-40 hours and required frequent bulb changes.

Consequently, in 1996 a compact combined IRSL/GLSL unit with a considerably improved sample-to-PM tube distance was developed [1]. Significant enhancement in the GLSL sensitivity was achieved by using a liquid lightguide system with high transmission ( $98 \%$ over $380-550 \mathrm{~nm}$ ) for the illumination of the sample. Filtered wavelength bands are provided using either a $150 \mathrm{~W}$ tungsten halogen lamp (life time: 2000 hours) or a $150 \mathrm{~W}$ xenon lamp, mounted in a remote lamp house and equipped with electromechanical shutter and exchangeable excitation filter pack. IRSL is stimulated using built-in IR LEDs focussed on the sample. A feed-back LED current control keeps the illumination constant during IR exposures. One of the diodes of the LED array faces a fibre lightguide which feeds the light output to a current controlling photo-transistor mounted in a constant temperature oven. The IRSL unit focuses the emitted luminescence onto a PM photo-cathode using a quartz lens with short focal length. A schematic diagram of the combined IRSL/GLSL unit is shown in Fig. 2A and the broad-band stimulation and detection filter characteristics are shown in Fig. 2B (the IR characteristics are the same as in Fig. 1B). 

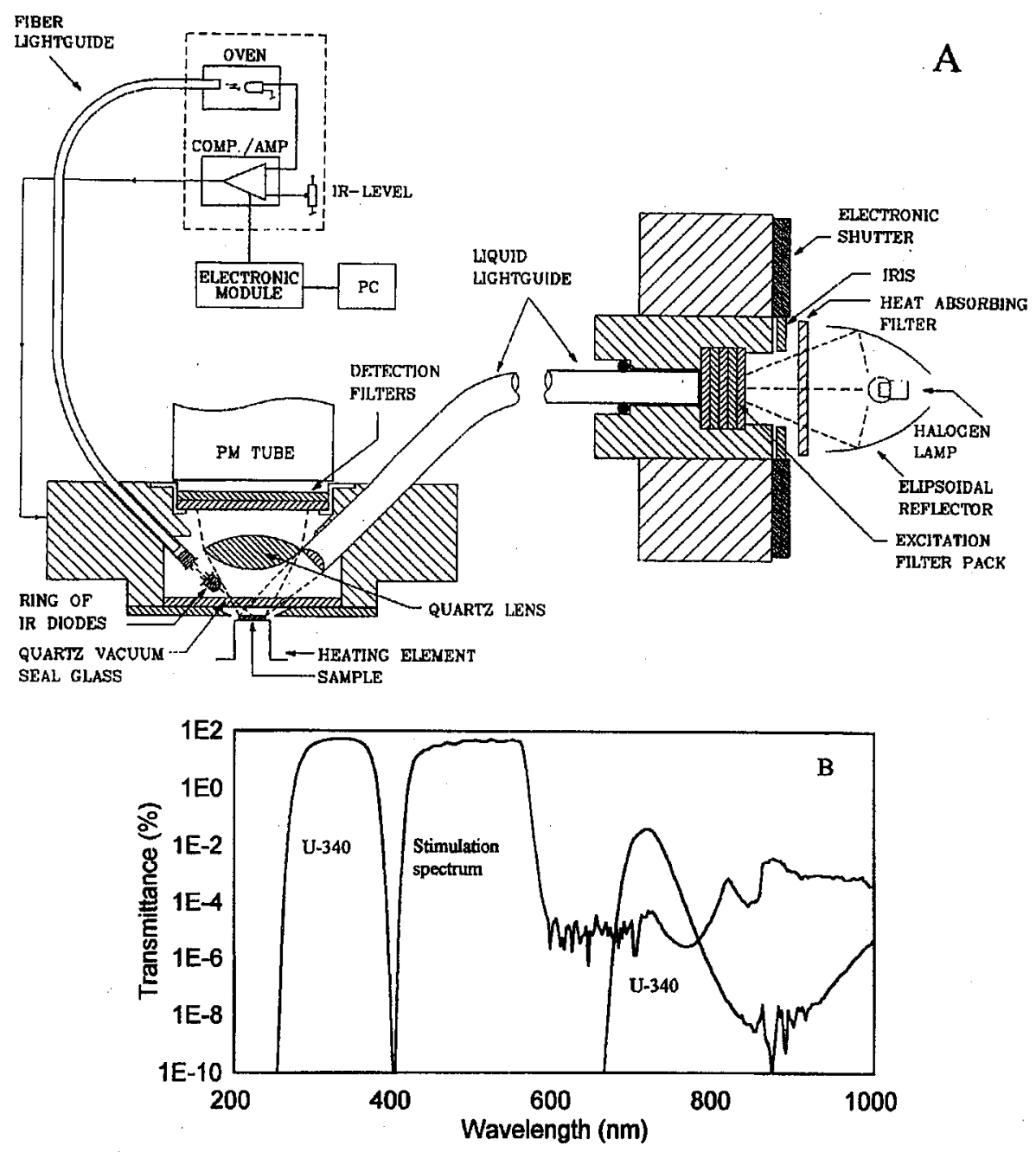

Fig. 2. (A) Schematic of the improved compact liquid lightguide-based combined IRSL LED and broad-band halogen lamp GLSL stimulation unit. The feedback system for controlling the IR LED current is also shown. (B) The stimulation and detection characteristics of the broad-band blue-green OSL unit (from Bøtter-Jensen et al. [21]).

\subsection{Automatic OSL scanner}

Poolton et al. [18] described an automatic system developed at Ris $\varnothing$ for measuring the age-related OSL of split sediment cores. The basis for the design is a core logger system with a conveyor belt allowing optical sensors to be moved along the length of split sediment cores up to the length of $1.7 \mathrm{~m}$. The optical sensor consists of a photo-excitation and detection module together with lamps for bleaching and regenerating the OSL. The OSL core scanner that uses both IR and green light stimulation was also used to measure depth dose profiles on small cores drilled out of bricks collected in nuclear accident areas for retrospective dose determination [19]. 


\subsection{Blue light LED stimulation}

A new type of bright green LEDs was used in a unit designed for the stimulation of quartz [20] where $50 \%$ deduction of the quartz signal in about $25 \mathrm{~s}$ was achieved, still significantly slower than the $\approx 5 \mathrm{~s}$ achieved with the latest Ris $\varnothing$ broad-band design. Recently, new bright blue LEDs have been tested at Ris $\varnothing$ for OSL illumination of quartz and porcelain samples [1, 21, 22]. When used in conjunction with a metal oxide coated U-340 detection filter, the emission from the blue LEDs needs to be filtered by a Schott GG- 420 cut-off filter in order to avoid the highest energy part of the LED emission spectrum interfering with the detection filter window [21]. An increase by the factor of 5 of OSL efficiency per unit power at the sample has been observed using blue LEDs on a variety of quartz and porcelain samples compared to that obtained using broad-band green light stimulation. Studies so far have shown that OSL signals from quartz behave similarly, whether stimulation is by blue LEDs or by broad-band green light [21, 22]. Blue LEDs offer several advantages over existing laser or broad-band stimulation sources. They are inexpensive and compact, and heat dissipation is negligible. Switch-on and -off times are much shorter than those which can be obtained with the electromechanical shutters used with halogen lamps and lasers. From an experimental point of view, the illumination power can be controlled electronically. This offers the possibility of software control during experimental sequences, e.g. to provide reduced power during brief illuminations used in normalisation, or to provide a time-varying stimulation power [22]. Figure 3 shows a schematic diagram of the most recently developed OSL attachment to the automated Ris $\varnothing$ TL/OSL

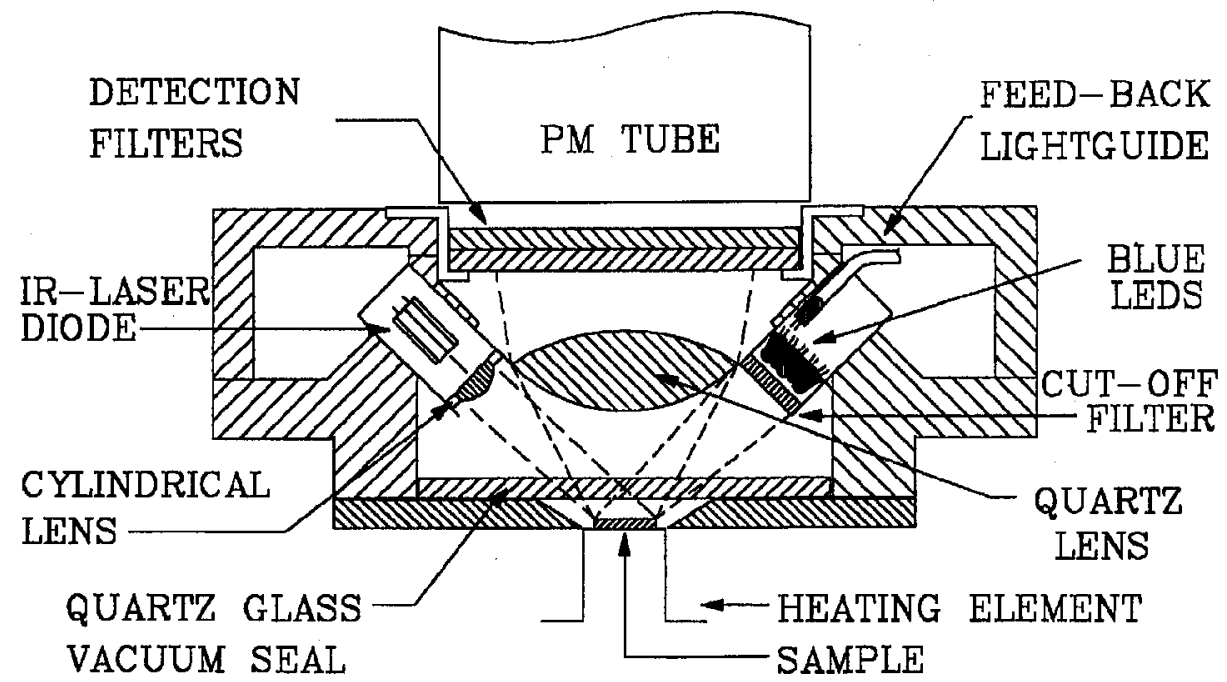

Fig. 3. Schematic of the new combined blue LED and IR laser diode OSL unit. 36 blue LEDs (in 6 clusters) emitting at $470 \mathrm{~nm}$ deliver maximally $24 \mathrm{~mW} / \mathrm{cm}^{2}$ at the sample and the IR laser diode emitting at $830 \mathrm{~nm}$ delivers maximally $550 \mathrm{~mW} / \mathrm{cm}^{2}$ at the sample. 
apparatus. The OSL system consists of six clusters of 6 blue LEDs and one IR laser diode arranged in a ring focusing the sample. The OSL unit delivers $24 \mathrm{~mW} / \mathrm{cm}^{2}$ and $650 \mathrm{~mW} / \mathrm{cm}^{2}$ from the blue LEDs $(470 \mathrm{~nm})$ and the IR laser diode $(830 \mathrm{~nm})$, respectively.

\section{Samples, analytical protocols and recent results}

As a part of the joint EU project "Dose Reconstruction", representatives from different participating laboratories took part in field trips to the nuclear accident areas in Russia and Ukraine (Chernobyl), where they collected materials that could be used as potential dosemeters for the reconstruction of the transient gamma doses received by the local population. Mainly bricks collected from buildings were used for luminescence measurements as they contain quartz and feldspar suitable for both TL and OSL measurements. The collaborative work between Ris $\varnothing$ and the University of Helsinki concentrated mostly on the extraction of quartz from bricks as material particularly suitable for OSL measurements. The following paragraphs describe recent techniques and analytical procedures used to perform measurements on the samples collected within the last two years and to determine the accrued gamma doses in extracted brick quartz.

\subsection{Sample preparation and experimental details}

Coarse quartz grains $(90-180 \mu \mathrm{m})$ were extracted from bricks for the OSL measurements. The bricks were sliced into $10 \mathrm{~mm}$ sections. Material from each section was crushed and treated with $10 \% \mathrm{HCl}, 40 \% \mathrm{H}_{2} \mathrm{O}_{2}$ and dry-sieved to separate the 90-180 $\mu \mathrm{m}$ grain size fraction. This fraction was then etched in $40 \%$ $\mathrm{HF}$ for 45 minutes to extract the quartz. An automated Risø TL/OSL reader, model Ris $\varnothing$ TL/OSL-DA-15, was used for the OSL measurements. The extracted quartz samples were stimulated using either broad-band blue-green stimulation light $(420-550 \mathrm{~nm})$ filtered from a halogen lamp delivering $28 \mathrm{~mW} / \mathrm{cm}^{2}$ to the sample [1] or blue LED stimulation $(470 \mathrm{~nm})$. Detection filters in all cases were $3 \mathrm{~mm}$ Hoya U-340. The quartz extracts were irradiated using a $185 \mathrm{MBq}{ }^{90} \mathrm{Sr}$ source delivering a dose rate of $8.2 \mathrm{mGy} / \mathrm{s}$ to the sample. The measurement sequences were performed using the Ris $\varnothing$ MiniSys sequence editor [23].

\subsection{Determining the transient accidental dose}

The total absorbed dose received by minerals within a ceramic sample is normally built up of two components: (i) the background dose due to naturally occurring radioactive isotopes in the surrounding media and (ii) the transient dose due to the sources introduced into the local environment by a incident radiation. The transient dose is the difference between the total dose delivered to the minerals (evaluated by luminescence measurements) and the accrued natural background dose. Thus the total dose, $D_{L}=D_{x}+A\left(D_{\alpha}+D_{\beta}+D_{\gamma}+D_{\mathcal{c}}\right)$ where $D_{x}$ is the cumulative transient gamma dose received by the ceramic sample due to artificial radioisotopes, $A$ is the sample age in years; $D_{\alpha}, D_{\beta}, D_{\gamma}$ and $D_{c}$ are effective annual alpha, beta, gamma, and cosmic ray doses, respectively, due to natural sources of radioactivity. Further details are reviewed by Bailiff [24] and Bøtter-Jensen et al. [25]. 


\subsection{Analytical protocol}

Using OSL facilities, the evaluation of the total gamma dose $\left(D_{L}\right)$ is usually made using either the additive-dose or the regenerative-dose protocols that had earlier been developed for TL (reviewed by Wintle [26]). These methods require several tens of sub-samples for a single estimation of $D_{L}$. One necessary requirement for the measurement of heterogeneous samples, and especially single grains, is an analytical protocol which allows all measurements required for the estimation of $D_{L}$ to be taken on one sub-sample (or aliquot). Recently, regenerative-dose single-aliquot protocols have been developed for quartz [27-30]. These methods are conceptually the simplest ones - the OSL is first measured and, in the process, the light-sensitive traps are emptied. A regeneration dose is then given, approximately equal to the total dose, and the OSL is measured again. If there has been no change in sensitivity, then $D_{L}$ is given by the ratio of the two OSL signals, multiplied by the known laboratory dose. In practice, however, there is usually a significant sensitivity change, especially if the sample is heated between dosing and measurement, and this prevented the application of this very simple approach in the past. However, recent work has shown that a precise correction for sensitivity can be made, based on the OSL signal from a small test dose given immediately after the natural or regenerated OSL measurement $[27,30]$.

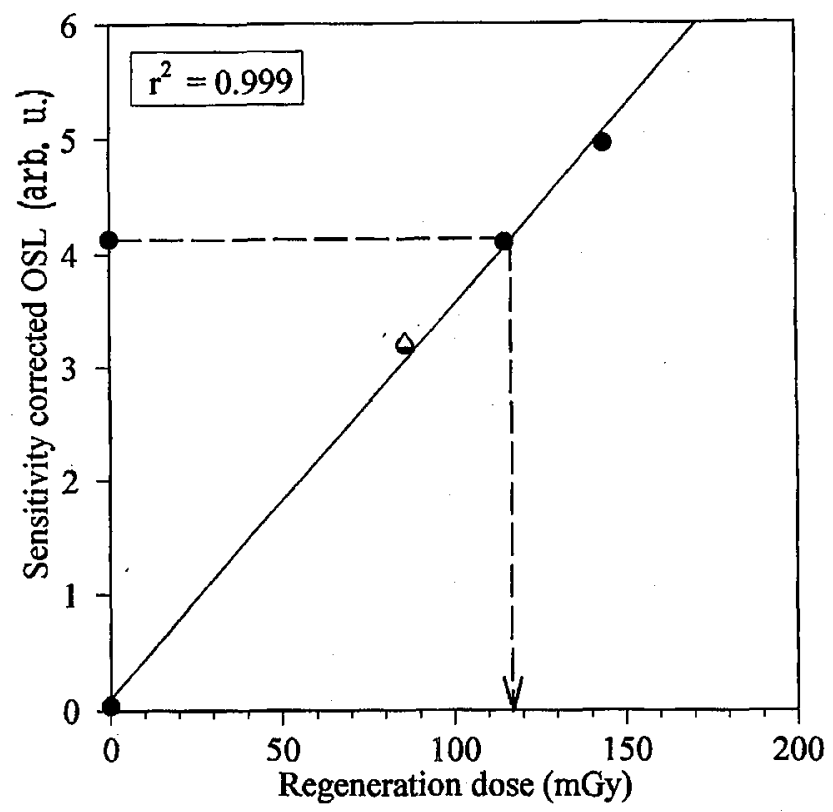

Fig. 4. Typical growth curve obtained from extracted brick quartz samples (4 mg) using blue LED stimulation and the single aliquot regeneration protocol. Note the repeated measurement of the first regeneration dose (unfilled triangle) that demonstrates the reproducibility. 
The dose evaluation of the extracted quartz grain samples described in this paper was based on a new single aliquot regeneration (SAR) protocol developed at Ris $\varnothing$ and described by Banerjee et al. [31]. This new protocol includes a method to compensate for any sensitivity changes occurring as a result of regeneration of the OSL signal. A small test dose is used to measure the OSL sensitivity appropriate to the regenerated signals; this is then used to correct for sensitivity changes [28]. In the work presented in this paper three regeneration doses were used to build the growth curve for interpolation of the unknown equivalent dose. Figure 4 shows a growth curve obtained using this protocol for extracted brick quartz. The sensitivity corrected data (obtained by dividing by the subsequent OSL test dose response) are shown as filled circles. After the OSL from a zero dose and from three regeneration doses were measured, a further fifth measurement was made at the lowest regenerated dose. The repeated measurement is shown as a filled triangle and demonstrates the high degree of reproducibility even for doses less than $100 \mathrm{mGy}$. The sensitivity corrected growth curve is linear $\left(r^{2}=0.999\right)$ and passes through the origin in this dose range.

\subsection{Recent results}

A variety of brick samples collected in the Chernobyl accident area during recent field trips in Russia and Ukraine had their content of quartz extracted according to the procedures described in Sec. 3.1. Subsamples of $4 \mathrm{mg}$ were used for the subsequent OSL measurements. In the retrospective assessment of accident doses using luminescence methods on bricks taken from buildings in accident areas it is important to measure the depth dose profiles into the brick material (OSL versus depth) to give information on the source distribution and the energy of the incident photon radiation [25]. For this reason it is desirable to compare such depth dose profiles with those obtained from bricks irradiated with known gamma sources in the laboratory. Also Monte Carlo simulations have been used for the control of experimentally obtained absorption curves. Samples for measuring depth dose profiles were prepared by slicing a cross-section of the brick into $10 \mathrm{~mm}$ subsections. Coarse grain $(90-150 \mu \mathrm{m})$ quartz samples were then extracted from each section as described in Sec. 3.1. For these samples the OSL signals were measured using either broad-band or blue LED stimulation sources as described in Secs. 2.2 and 2.4, respectively. Figure 5A shows a typical OSL decay curve obtained from a quartz sample with a natural background dose of approximately $100 \mathrm{mGy}$. Figure 5B shows typical depth dose profiles obtained from Chernobyl bricks using blue LED stimulation and the single aliquot regeneration protocol. Approximately 15 single aliquot dose determinations per point were used and the average calculated precision was in the order of $1-2 \%$. It should be noted that the error bars are within the symbols. As it can be seen, the upper curve represents the results from a brick irradiated from one side to an external accidental photon dose. The exponential decay rate is in agreement with that obtained from a brick irradiated to $660 \mathrm{keV}{ }^{137} \mathrm{Cs}$ gamma photons in the laboratory. The lower curve represents a brick that has not been exposed to any significant external dose other than those from the internal radionuclides in the material and the ambient photon radiation including the cosmic radiation. 

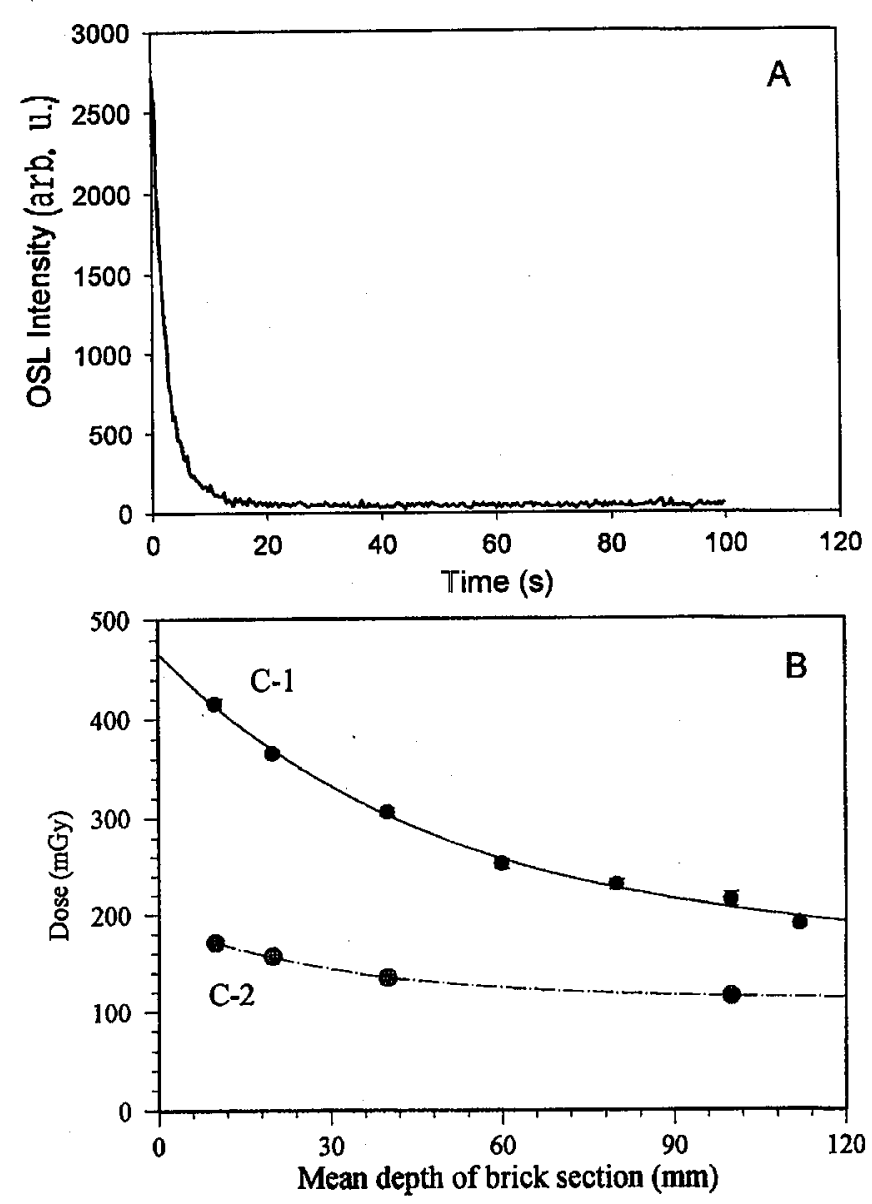

Fig. 5. (A) Typical OSL decay curve obtained from extracted brick quartz (4 mg samples) using blue LED stimulation $\left(18 \mathrm{~mW} / \mathrm{cm}^{2}\right)$. Natural dose: approximately $150 \mathrm{mGy}$. (B) Depth dose profiles into bricks collected in the Chernobyl area obtained from extracted quartz using blue LED stimulation. The shape of C-1 mostly represents the contribution from the external incident radiation. The shape of $\mathrm{C}-2$ mostly represents the contribution from the natural background radiation. The overall precision obtained per point is $1-2 \%$ (the error bars are within the symbols).

\section{Conclusions}

We have described the continuing development of OSL techniques for retrospective assessment of accident doses using natural materials extracted from bricks carried out at Ris $\varnothing$. Both for quartz and feldspar, we have now cheap, readily available stimulation sources which can reduce OSL signals to small fractions of their initial values in no more than a few seconds. LED based light sources offer electronic control and rapid switching times.

We have also described sample preparation methods and recently developed analytical protocols based on the single aliquot regeneration method. We have 
moreover presented recent results from measurements on extracted quartz from bricks collected in the Chernobyl accident area. Using the single aliquot regeneration method OSL depth dose profiles were measured in the $100 \mathrm{mGy}$ range with an overall precision of $1-2 \%$.

We conclude that OSL techniques have proven to be very easy, sensitive, and reproducible in the retrospective assessment of doses using natural quartz and feldspar as accident dosemeters.

\section{Acknowledgment}

This work was partly funded by the EU research project "Dose Reconstruction". We are grateful to D. Banerjee for his valuable help with sample preparation and OSL measurements.

\section{References}

[1] L. Bøtter-Jensen, Radiat. Meas. 27, 749 (1997).

[2] D.J. Huntley, D.I. Godfrey-Smith, M.L.W. Thewalt, Nature 313, 105 (1985).

[3] M.J. Aitken, Archaeometry 32, 19 (1990).

[4] D.I. Godfrey-Smith, D.J. Huntley, W.-H. Chen, Quat. Sci. Rev. 7, 373 (1988).

[5] E.J. Rhodes, Quat. Sci. Rev. 7, 359 (1988).

[6] G. Hütt, I. Jaek, J. Tchonka, Quat. Sci. Rev. 7, 381 (1988).

[7] N.R.J. Poolton, I.K. Bailiff, Ancient TL 7, 18 (1989).

[8] N.A. Spooner, M.J. Aitken, B.W. Smith, M. Franks, C. McElroy, Radiat. Prot. Dosim. 34, 83 (1990).

[9] L. Bøtter-Jensen, C. Ditlevsen, V. Mejdahl, Nucl. Tracks Radiat. Meas. 18, 257 (1991).

[10] L. Bøtter-Jensen, G.A.T. Duller, Nucl. Tracks. Radiat. Meas. 20, 549 (1992).

[11] L. Bøtter-Jensen, S.W.S. McKeever, Radiat. Prot. Dosim, 65, 273 (1996).

[12] L. Bøtter-Jensen, B.G. Markey, N.R.J. Poolton, H. Jungner, Radiat. Prot. Dosim. 65, 369 (1996).

[13] L. Bøtter-Jensen, N. Agersnap Larsen, B.G. Markey, S.W.S. McKeever, Radiat. Meas. 27, 295 (1997).

[14] N.A. Spooner, D.G. Questiaux, in: Synopsis from a Workshop on Long and Short Range Limits in Luminescence Dating, Oxford 1989, The Research Laboratory for Archaeology and the History of Art, Occasional Publication No. 9, Oxford University, Oxford 1990, p. 97.

[15] D.I. Godfrey-Smith, M. Cada, Radiat. Prot. Dosim. 66, 379 (1996).

[16] L. Bøtter-Jensen, A.S. Murray, Radiat. Prot. Dosim., in press.

[17] A.G. Wintle, Nature 245, 143 (1973).

[18] N.R.J. Poolton, L. Bøtter-Jensen, A.G. Wintle, P.J. Ypma, K.L. Knudsen, V. Mejdahl, B. Mauz, H.E. Christiansen, J. Jakobsen, F. Jørgensen, F. Willumsen, Boreas 25, 195 (1996).

[19] L. Bøtter-Jensen, H. Jungner, N.R.J. Poolton, Radiat. Meas. 24, 525 (1995).

[20] R.B. Galloway, D.G. Hong, H.J. Napier, Meas. Sci. Technol. 8, 267 (1997). 
[21] L. Bøtter-Jensen, V. Mejdahl, A.S. Murray, Quat. Sci. Rev., in press.

[22] L. Bøtter-Jensen, G.A.T. Duller, A.S. Murray, D. Banerjee, Radiat. Prot. Dosim., in press.

[23] B.G. Markey, L. Bøtter-Jensen, G.A.T. Duller, Radiat. Meas. 27, 83 (1997).

[24] I.K. Bailiff, Radiat. Meas. 27, 923 (1997).

[25] L. Bøtter-Jensen, D. Banerjee, H. Jungner, A.S. Murray, Radiat. Prot. Dosim., in press.

[26] A.G. Wintle, Radiat. Meas. 27, 769 (1997).

[27] A.S. Murray, R.G. Roberts, A.G. Wintle, Radiat. Meas. 17, 171 (1997).

[28] A.S. Murray, V. Mejdahl, Quat. Sci. Rev. (Quaternary Geochronology), in press.

[29] K. Strickertsson, A.S. Murray, Quat. Sci. Rev. (Quaternary Geochronology), in press.

[30] A.S. Murray, R.G. Roberts, Radiat. Meas., in press.

[31] D. Banerjee, L. Bøtter-Jensen, A.S. Murray, Radiat. Prot. Dosim., in press. 